\title{
ESTUDIO COMPARATIVO DE DIFERENTES MODELOS DE ANÁLISIS DOCUMENTAL DE FOTOGRAFÍAS
}

\section{COMPARATIVE ANALYSIS REGARDING DIFFERENT MODELS FOR DOCUMENTAL ANALYSIS OF PHOTOGRAPHS}

\author{
AUTORA \\ Eva de la Parra López \\ Universidad de Alcalá de Henares, Madrid (España) \\ evadelaparra@gmail.com
}

\section{RESUMEN}

Este trabajo tiene como objetivos conocer, analizar y comparar diferentes modelos para el análisis documental de la imagen fija propuestos en los últimos años por autores españoles o bien existentes como normas y recomendaciones a nivel internacional. A través de ellos se ha analizado una selección de imágenes comparando resultados, teniendo en cuenta al usuario final y la eficiencia que aportan en la recuperación de información. Los modelos analizados han sido las ISBD (NBM), ISAD (G), recomendaciones de SEPIADES, y modelos elaborados por los autores García Marco y Agustín Lacruz, Valle Gastaminza, Robledano Arillo, y el grupo de investigación del Área de Comunicación Audiovisual y Publicidad de la Universidad Jaume I de Castellón. Los datos obtenidos nos permiten conocer el estado actual de las investigaciones y nos sirven como ejemplo sobre el desarrollo práctico del análisis documental en los centros españoles, la disparidad de modelos existentes y los retos a afrontar en el futuro en cuanto a la unificación de criterios, normalización de formatos y elaboración de lenguajes controlados específicos para la imagen. 


\section{PALABRAS CLAVE}

Documentación fotográfica - Fotografías - Análisis documental - Estudio comparado.

\section{ABSTRACT}

This paper presents a study of several models for analysing photos. We study several authors in this field and several standards as well. The models and standards analyzed have been ISBD (NBM), ISAD (G), SEPIADES recommendations, and models by authors such as García Marco and Agustín Lacruz, Valle Gastaminza, Robledano Arillo, and research team from Universidad J aume I de Castellón.

\section{KEY WORDS}

Images documentation - Photographs - Analysis - Comparision.

\section{ÍNDICE}

\section{Introducción}

2. La fotografía como documento no textual

3. El análisis documental de la imagen fotográfica

4. Modelos para el análisis documental de fotografías

5. Conclusiones 


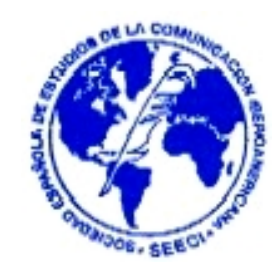

\section{Introducción}

Tradicionalmente la literatura científica desarrollada sobre el análisis documental se ha centrado sobre todo en el estudio de la documentación textual. El texto, junto con la transmisión oral, han sido los medios de comunicación y transmisión de la información y los conocimientos por excelencia hasta bien entrado el siglo XX. Cuando en el siglo XIX apareció la fotografía lo hace también una nueva forma de transmitir y de comunicar, un nuevo modo de expresión, que crece convirtiéndose en un medio de comunicación fundamental sobre todo con la aparición de la imagen en movimiento como vemos en esta nueva sociedad del siglo XXI en la que la imagen adquiere cada vez más importancia. De esta presencia surge la necesidad de llevar a cabo la realización de trabajos y estudios centrados en el análisis documental de la imagen, además estos documentos están apareciendo cada vez con más fuerza en nuestros archivos y centros de documentación, documentos que como los demás debemos de difundir y sobre los que hay cada vez mayor demanda. El análisis documental será clave para determinar su acceso y difusión.

Hasta no hace muchos años se ha utilizado el paradigma textual para el análisis de las imágenes, pero este paradigma resulta claramente insuficiente e insatisfactorio como método de análisis del contenido informativo de unos documentos cuya textualidad es un elemento decreciente en importancia frente a la iconocidad (Agustín, 1997). No sólo en cuanto al análisis documental sino que la mayoría de lenguajes documentales que se utilizan en su tratamiento parten de un enfoque eminentemente textual. Son documentos que hoy por hoy están totalmente integrados en los catálogos y cuyas formas de acceso a los mismos siguen siendo eminentemente literarias. En los últimos años aparecen autores que centran sus estudios en la imagen como documento portador y transmisor de información y conocimiento, desde un punto de vista documental y con unas características propias y peculiares que la distinguen de los documentos textuales. Estos autores han desarrollado propuestas sobre cómo llevar a cabo el análisis documental de los 


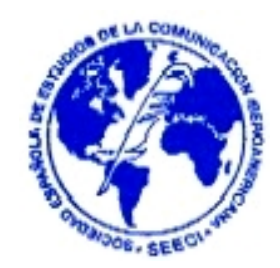

documentos no textuales estableciendo modelos que sirvan de referencia y ayuda para el trabajo diario de archivos, bibliotecas y centros de documentación. El objeto de estudio de este trabajo van a ser estos modelos para el análisis documental de la imagen fija propuestos en los últimos años por autores españoles o bien normas 0 recomendaciones para este análisis existente a nivel internacional.

Los objetivos de este trabajo serán recopilar y dar a conocer los diferentes modelos propuestos y analizarlos y compararlos teniendo siempre como perspectiva final la recuperación de información por parte de los usuarios. El propósito será conocer a través de su comparación los métodos e instrumentos de análisis más adecuados para garantizar que con su utilización se responde a las demandas informativas puestas de manifiesto por los usuarios, por tanto siempre orientado a la recuperación. Se estudia la adecuación de estos modelos en sistemas automatizados eficaces para el tratamiento y recuperación de la información así como su eficiencia para los distintos centros que los adapten como métodos de análisis documental teniendo en cuenta los recursos humanos, tecnológicos, económicos, etc., que sean necesarios en su implantación. Para introducirnos en la comprensión de los modelos vamos a comenzar viendo cómo la fotografía es un documento con unas particularidades que lo distinguen en su análisis de los documentos textuales y por tanto cómo debe ser objeto del análisis documental de manera diferenciada a otro tipo de documentos además de cuáles son estas particularidades. Además esto nos servirá para ver si los modelos tienen en cuenta estas peculiaridades y favorecen un completo análisis documental con todos aquellos elementos que son necesarios para la recuperación.

\section{La fotografía como documento no textual}

Cuando nos referimos en este trabajo a la fotografía se hace desde el punto de vista de una imagen fija, almacenada o que se almacenará en un archivo fotográfico (bien sea archivo, biblioteca o centro de documentación) que ha sido usada o existe una 


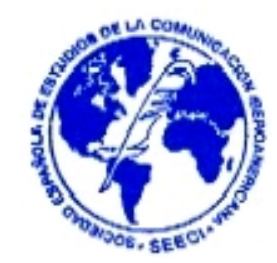

previsión de su uso para un usuario determinado, que contiene un mensaje para ese usuario, y que como portadora de información y por su posible uso debe de ser almacenada y tratada documentalmente para poder ser posteriormente recuperada con eficacia. Esta fotografía es producto de un acto intelectual, es una obra de carácter intelectual y como tal está protegida legalmente. En el ámbito español, que nos afecta, está protegida por la Ley de Propiedad Intelectual de $1996^{1}$.

La imagen tiene unas características peculiares que la distinguen de otro tipo de documentos sobre todo en comparación con los textuales y que como ellos es un potente modo de comunicación. Comunica ideas, pensamientos, a través de códigos no alfabéticos y por tanto su significado puede interpretarse en cualquier idioma. Esto hace que tenga un gran poder comunicativo. Por otro lado la información que contiene suele ser más desestructurada que la verbal como coinciden en señalar García Marco y Agustín Lacruz (García, 1999). Estas estructuras están sobre todo en relación con la interpretación que cada uno hagamos de una imagen. A la hora de percibir una imagen lo hacemos de una vez, mientras que la percepción de un documento textual es progresiva. La información vehiculada por una imagen se hace a través de dos tipos de signos los icónicos, la propia imagen, y los lingüísticos, pie de foto que acompaña a la imagen para explicarla. La imagen, al contrario que el texto, no tiene capacidad de informar sobre lo que trata, para hacerlo tiene que ayudarse de un texto lingüístico que la acompañe. Lo que la diferencia de cualquier otro tipo de documentos es su carácter primordialmente icónico, es su atributo por excelencia. A la hora de comunicar la imagen tiene la capacidad de evocar sensaciones y percepciones de una manera muy fuerte, su poder como referente es mayor que cualquier otro medio de representación. Por otro lado, la imagen a diferencia del texto, siempre debe estar ligada al contexto, en ella es difícil hablar de el significado de sus signos sin que éstos se relacionen con el contexto con en que se desarrollaron, la imagen por sí misma, sin ese contexto puede ser muy ambigua.

\footnotetext{
${ }^{1}$ Real Decreto Legislativo 1/1996, de 12 de abril, por el que se aprueba el Texto refundido de la Ley de Propiedad Intelectual.
} 


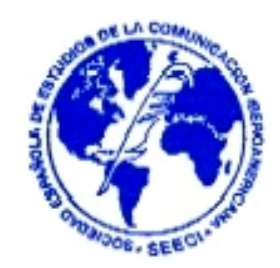

Desde el punto de vista físico se puede hablar del polimorfismo de la fotografía. Una misma imagen se puede presentar en multitud de formas y soportes. Entre estas formas y soportes nos podemos encontrar con negativos, planchas de contacto, diapositivas, copias positivas en papel, negativos de reproducción, copias impresas, ficheros digitales obtenidos de distintas maneras, etc. Son documentos que se nos presentarán en múltiples formas y que deberemos tener en cuenta.

Al hablar de la imagen como documento no podemos dejar de lado una de sus características más importantes: su polisemia. Su significado cambia con el tiempo, con el contexto en el que se encuentra, con el lector que la interpreta, etc. En realidad más que poseer un significado podríamos decir que el significado muchas veces se lo da su uso. Podemos decir que principalmente una fotografía significa cosas diferentes en tres momentos diferentes como son la creación, lo que significa para el fotógrafo, en el momento del tratamiento documental, lo que significa para el documentalista que la interpreta, y en el momento de su reutilización, lo que significa para el usuario que la recupera (Valle, 2001). Estas posibilidades de lectura que ofrece una fotografía deben ser tenidas en cuenta por los analistas de las imágenes. Sara Shatford (Shatford, 1994) destaca con respecto a esta polisemia otros atributos a tener en cuenta como son que una imagen puede ser "de algo" y a la vez "sobre algo", lo que supone una dualidad de significados y también puede ser genérica y específica a la vez, atendiendo por ejemplo a quien la perciba. Pero de la fotografía no sólo tenemos que destacar sus diversos significados sino también sus distintos niveles de significación. Al hablar de estos niveles autores como García Marco y Agustín Lacruz (García, 1999) y el profesor Moreiro (Moreiro, 2001) entre otros coinciden en destacar tres niveles de significación de los que ya había hablado Panofsky en su obra El significado de las artes visuales y que ellos centran en el campo de la documentación. El primer nivel corresponde a un nivel de descripción pre-iconográfica, es un nivel identificador de formas, con información de la imagen como documento y los objetos que contiene. Luego tendríamos un segundo nivel de análisis iconográfico, descriptivo, en donde se identifica cada objeto y cada concepto 


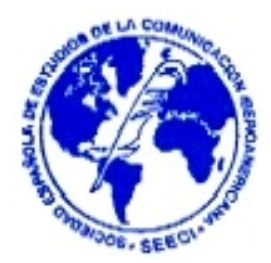

con precisión. El tercer nivel sería el de interpretación iconológica que supone la interpretación del conjunto de la imagen, de los objetos y conceptos. Aunque no todas las imágenes son susceptibles de poseer estos tres niveles.

Todos estos rasgos señalados caracterizan, sin lugar a dudas, a la imagen como documento que debe ser tratado documentalmente de manera distinta, atendiendo a estas características.

\section{El análisis documental de la imagen fotográfica}

El objetivo del análisis documental de una imagen fotográfica va a ser principalmente su recuperación, se analiza un documento para recuperarlo posteriormente. Además el análisis nos facilitará su control y localización. Félix del Valle (Valle, 1994) nos habla de dos niveles en el análisis documental de fotografías: un nivel morfológico, en donde se estudian las características técnicas, formales y de composición de la imagen y un segundo nivel con un análisis de contenido que afecta a lo fotografiado y a sus posibles significados. A estos dos niveles habría que añadir todos los datos de identificación de las imágenes, atributos biográficos de la misma, como son autor, fecha, publicación, título, lugar, usos, derechos, etc. A estos atributos biográficos también se les denomina análisis formal o externo. Esta es la parte más controlada en actualidad dentro del análisis de fotografías existiendo normas internacionales que limitan la descripción de rasgos formales y que son similares a la descripción del resto de tipologías documentales, es sin duda la parte más normalizada y por tanto la que más posibilita el compartir información. Dentro de estas normas nos encontramos por ejemplo con las ISBD $(\mathrm{NMB})^{2}$, que veremos más adelante desarrollado en el análisis de imágenes. En el ámbito archivístico las normas ISAD

\footnotetext{
2 ISBD(NMB): International Standard Bibliographic Description for Non-Book Materials. Descripción bibliográfica internacional normalizada para materiales no librarios.
} 
$(G)^{3}$ para la creación de registros documentales son las más desarrolladas y que también veremos ejemplos de análisis más adelante.

En cuanto al análisis de contenido es la parte que está menos normalizada dentro del análisis documental y con la que surgen más problemas en el análisis de la fotografía. Al analizar una fotografía nos encontramos con tres aspectos fundamentales: la denotación, lo que aparece en la imagen, la connotación, lo que sugiere la imagen, y el contexto en el que se produce (Valle, 2002). Si no se tienen en cuenta estos tres aspectos el análisis de la fotografía no será completo.

La denotación es la relación directa entre el significante y el significado, es la parte más objetiva y por tanto la que da menos problemas en la indización y a la vez es la que produce menos inconsistencia entre diferentes indizadores. Son todas aquellas formas que se reconocen de forma unívoca entre el emisor y el receptor. Son muchos los autores los que recurren a una conocida técnica periodística para averiguar todo el contenido denotado en una imagen como es la aplicación en parte de las cinco $\mathrm{W}$ de la noticia periodística: averiguar ¿quién aparece en la fotografía? (Who?), ¿qué situación u objetos están representado? (What?), ¿dónde se ha tomado y qué lugar representa? (Where?), ¿cuándo se ha hecho la toma? (When?) y ¿cómo?, describiendo acciones de las personas.

La connotación es todo aquello que no aparece directamente en la imagen pero que sin embargo lo sugiere. Es la parte más subjetiva porque las sugerencias, como se ha dicho en cuanto a la polisemia de la imagen, dependen del lector, del contexto, incluso puede haber numerosos condicionantes sociales en la lectura que hagan interpretar de una manera distinta una misma imagen. Dentro de la connotación de las imágenes hay también una parte más subjetiva o otra más objetiva. Por ejemplo socialmente, en una cultura occidental, la representación de una paloma nos sugiere un concepto abstracto como es "paz". Este tipo de sugerencias, condicionadas

\footnotetext{
${ }^{3}$ ISAD(G): General International Standard Archival Description. Norma internacional general de descripción archivística.
} 


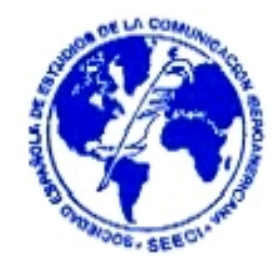

fuertemente por el entorno socio-cultural, pueden dar una mayor coincidencia en los criterios interpretativos. Moreiro (Moreiro, 2001) habla de la denotación y la connotación como características contrapuestas que intervienen en la lectura de la imagen y de las que señala: la denotación es objetiva, convergente, literal, informativa, patente, obvia, explícita, visible, práctica, superficial, cerrada, cognoscitiva, fáctica, lógica, se ven por la acción lógica, primaria, querida por el emisor, representación, clara, concreta, dicho, simple, codificado, se ve con los ojos, y es monosémica. Por otro lado de la connotación dice que es subjetiva, divergente, arbitraria, interpretativa, latente, obtusa, implícita, oculta, mítica, profunda, abierta, emotiva, persuasiva, psicológica, se ven por contemplación, secundaria, querida por el receptor, evocación, desvaída, abstracta, sugerida, compleja, libre, no se ve con los ojos y es polisémica. Sin duda esta contraposición de elementos nos hacen ver claramente las diferencias entre las características denotadas y connotadas por las imágenes y que debemos tener en cuenta a la hora de realizar su lectura.

La tercera parte que dijimos que había que tener en cuenta era el contexto, es el marco en el que se sitúa la imagen y que es fundamental para su correcta comprensión.

Toda esta parte subjetiva es algo característico del análisis de las imágenes que no encontramos, o no deberíamos encontrar, en el análisis de documentos textuales. Cierta subjetividad es aceptada en el análisis de fotografías puesto que lo que una imagen sugiere, por definición, es subjetivo para cada persona o grupo de personas, pero su análisis es tan importante como el de la parte denotada. Cierto ruido en la localización de estos documentos puede permitirse porque al ser recuperados el ojo humano puede leer una imagen en cuestión de segundos y descartar aquellas que no sean pertinentes de una manera bastante rápida, algo que no ocurre con los textos donde un exceso de respuestas será mucho más perjudicial. Silvia Domènech (Domènech, 1999) nos da una serie de consejos para evitar la subjetividad en la indización de fotografías: indizar los conceptos y los objetos contenidos, indizar los 


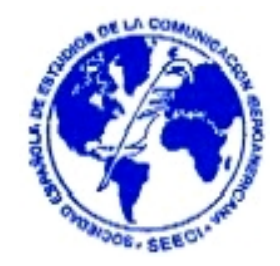

contenidos fundamentales de cada imagen no todo lo que aparece, elaborar unas normas de indización seguidas por todos los indizadores, distinguir los tipos de documentos a indizar, definir claramente el tipo de usuarios a quienes nos dirigimos, definir el nivel de descripción más genérico o específico, determinar la especificidad temática y controlar el trabajo de los indizadores.

Para completar el análisis de contenido de la fotografía habría que tener en cuenta las relaciones que puedan tener con otros documentos textuales o iconográficos (Valle, 2002).

A la hora de afrontar el análisis documental se hará en diversas fases con una lectura del documento donde se tendrá en cuenta el contenido iconográfico de la imagen y todos aquellos elementos textuales que puedan acompañarla y que nos aportarán información primordial en su descripción. Se identifican los elementos de la fotografía y se relaciona con el contexto de producción. Después se hará el estudio de las connotaciones. Se eligen los conceptos candidatos a representar el contenido y se traducen a un lenguaje normalizado en caso de que el centro que realiza el análisis lo requiera. Los descriptores que representan el contenido de las imágenes deben ser de dos tipos (Madrid, 1997): descriptores referenciales, que son la expresión de la descripción y la iconografía, y descriptores no referenciales, que identifican elementos que no están presentes en la imagen pero que tienen relación con ella.

La normalización en todos estos procesos sería deseable porque al unificar los formatos se facilita el acceso a los usuarios y no que tendrán que aprender cómo acceder a un documento cada vez que lo hagan en un centro distinto. Además normalizar facilita el intercambio de información entre los centros. Esta normalización se ha pensado tradicionalmente para normas descriptivas así como para formatos estandarizados de intercambios de registros, para lenguajes documentales que ayuden en el tratamiento de las imágenes, etc. La necesidad de normalización en cuanto a la descripción por los beneficios que aporta es lo que ha llevado a diversos 


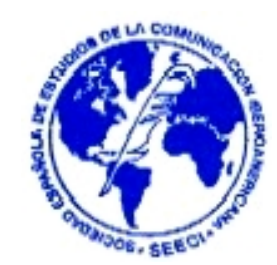

autores a proponer modelos de descripción tratando de generalizar su uso en diferentes centros e instituciones.

\section{Modelos para el análisis documental de fotografías}

A continuación se van a analizar diferentes modelos propuestos por autores españoles para llevar a cabo un análisis documental de documentos no textuales, imágenes fijas. La propia multiplicidad de modelos existentes nos señala como no se ha llegado a una normalización aceptada por una mayoría y casi podríamos decir que hay tantos modelos como centros que conservan y difunden este tipo de documentos. Éstos desarrollan modelos ad hoc y normalmente incluyen una parte de descripción formal con lo que la poca normativa existente apenas se aplica al análisis.

Para llevar a cabo este estudio se ha realizado una revisión bibliográfica de la literatura científica en lengua española sobre el análisis documental de la fotografía con la finalidad de conocer qué se está haciendo en nuestros centros en este terreno y qué proponen nuestros investigadores para realizar este análisis de la manera más eficiente. Se han seleccionado una serie de modelos cuyas características los diferencian unos de otros sustancialmente como para poder compararlos entre sí descartando aquellos que eran demasiado similares o no aportaban un modelo real sino sólo pequeñas variaciones a un modelo ya existente, como por ejemplo métodos que parten de la base de las ISAD (G) con algunas adaptaciones concretas a las necesidades de un centro. Se exponen los modelos propuestos a través de la definición y descripción de los campos y contenidos que los autores consideran absolutamente necesarios para el tratamiento documental de imágenes. En todos se da la referencia bibliográfica del modelo original para poder acudir a él en caso de que se desee y ampliar la información sobre el mismo. 


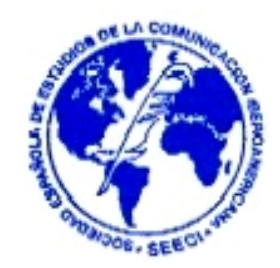

Una vez analizados los modelos se va a realizar un trabajo de campo aplicándolos a un conjunto de fotografías para ver cómo se comportan en la práctica y no sólo en la teoría del análisis. Se han seleccionado cinco imágenes para realizar el estudio habiendo utilizado como criterio principal en su elección el que tuvieran una gran cantidad de información tanto a nivel de información denotada como connotada y e información conocida de contexto, imágenes en las que se apreciaban muy claramente todas las características que hemos visto anteriormente que definen al documento iconográfico frente al documento textual. Además se ha intentado abarcar una representación de algunas de las diferentes temáticas que podemos encontrar en un centro. Se es consciente de que para una correcta evaluación de los modelos se debería llevar a cabo un análisis sobre un universo de fotografías mucho mayor y analizar el mismo grupo de imágenes con todos y cada uno de los modelos pero esto no ha sido posible porque desbordaría el motivo y la finalidad de este trabajo. Sin duda la parte analizada nos va a permitir extraer unas conclusiones generales que nos den una idea de lo que se ha pretendido analizar. Se comienza con modelos dedicados a un análisis prácticamente formal para avanzar hacia otros cada vez más desarrollados.

Con cada modelo se ha realizado el análisis de al menos una imagen, dependiendo de la extensión y profundidad del mismo, y los resultados se presentan junto con las imágenes como anexos a este trabajo. En algunos casos ha sido necesario completar el contenido de algunos campos con datos no reales como número de registro, poseedores de los derechos de autor, etc. para poder ver la aplicación completa del modelo. La simulación de estos datos nos permitía hacernos una mejor idea del resultado final y real del análisis. Las fotografías seleccionadas han sido:

- Retrato de Inocencio X, Diego Rodríguez de Silva Velázquez

- Iranian women preparing to vote, Christine Spengler

- Muerte de un miliciano, Robert Capa

- Tú que no puedes, Francisco de Goya y Lucientes

- Expedicionarios, Rafael Castro y Ordóñez 


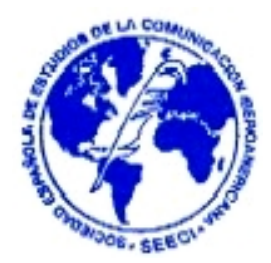

\subsection{ISBD(NBM)}

Vamos a comenzar con este sistema de descripción de materiales no textuales como ya se ha dicho es de las pocas normalizaciones existentes a nivel nacional e internacional. Para conocer cómo se ajustan estas normas a la descripción de fotografías vamos a seguir a dos autoras como son Adelina Clausó García (Clausó, 1999) e Isabel Ortega (Ortega, 1999) a través de la interpretación de las Reglas de Catalogación españolas. A ellas se tendría que acudir para conocer puntuación prescrita para cada área en las que se divide el asiento, fuentes de información para la descripción de las obras, lenguas a utilizar, erratas, etc. Aquí nos limitaremos a repasar aquellos datos fundamentales que deben ser incluidos a la hora de la catalogación y una breve descripción de los mismos.

Como datos fundamentales que debe incluir una catalogación para materiales fotográficos basándose en las ISBD (ISBD 1993) son: título, autor, datos de publicación, lugar, fecha o fechas, descripción física, números de control y notas.

- Los títulos en fotografías se darán en caso de conocerse y en muchas ocasiones serán asignados por el propio catalogador. Suele ser una descripción breve del contenido y podrán darse títulos paralelos en caso de que existan.

- El autor o autores de la fotografía se registran tal y como aparecen en la fotografía. Se harán entradas por cada autor de la obra. En los casos de reproducciones de obras de arte el autor principal es siempre el fotógrafo, en caso de ser conocido, y se hará una entrada para el autor de la obra de arte original. Si la obra es anónima o no se conoce al autor se registrará como tal "Anónimo".

- Los datos de publicación, lugar, editor y año, se darán en caso de que proceda. En caso de que los materiales no hayan sido publicados sólo se indica la fecha, que corresponde a la que se produce la fotografía. 


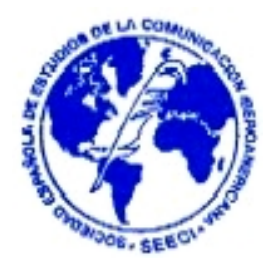

- La descripción física trata la extensión y designación de material, dimensiones y material anejo o complementario.

- En el área de notas es la parte donde se asienta toda la información que no haya podido meterse en las demás áreas o información complementaria que se considere oportuna para la correcta identificación de la obra. En las notas se darán también las restricciones de uso de una obra.

Isabel Ortega habla de completar esta catalogación con una catalogación temática o clasificación para asentar los contenidos relevantes que pueda tener una obra utilizando autoridades de persona, entidad y geográficas así como encabezamientos de materia o tesauros.

\subsection{ISAD(G)}

Las ISAD(G) como se ha dicho anteriormente es la norma general utilizada en la descripción de archivos. Son muchos los autores que recomiendan su utilización para la descripción de materiales gráficos, sobre todo en cuanto a atributos bibliográficos y técnicos de las fotografías. Las ISAD se basan en unas reglas de descripción que van de lo general a lo específico, proporcionando una descripción adecuada dependiendo del nivel en que nos encontremos ya que se basan en la descripción multinivel. Cada descripción se relaciona con la unidad inmediatamente superior y no debe repetirse información de unos niveles a otros.

Los elementos utilizados en la descripción pueden seleccionarse de entre el total que da la norma. Vamos a seguir un modelo propuesto por Ruiz Rodríguez y Álamo Fuentes en el año 1998, basado en una adaptación de las ISAD (ISAD 2000) para la descripción de materiales fotográficos a nivel de documento simple, que en archivos es el menos desarrollado. Estos autores plantean, dentro de la norma, qué elementos consideran realmente imprescindibles para conseguir un adecuado equilibrio en la descripción. Los campos, repartidos en áreas, son: 
1. Área de identificación

- Código: código del país, código del archivo más la signatura de la unidad documental.

- $\quad$ Nivel de descripción: especificando en qué nivel nos encontramos. Es la situación de la unidad de descripción en la jerarquía del fondo. (Fondo, subfondo, serie, subserie, unidad documental compuesta, unidad documental simple). Aquí añaden al nivel de descripción el título conformando una sola frase.

- Fecha: la de creación asumiendo las fechas extremas cuando se necesite.

- Volumen de la unidad de descripción: Se aludirá a la cantidad, tipo de soporte, tamaño y proceso de creación.

2. Área de contexto:

- Nombre del productor: debe contemplar el autor de la fotografía y el responsable jurídico de la misma.

3. Área de contenido y estructura

- Resumen: Descripción escueta de lo que vemos citando aspectos de la imagen que puedan orientar al usuario.

4. Área de condiciones de acceso:

- Características físicas: información sobre el estado de conservación, proceso de creación, soporte, agentes degradantes y aspectos físicos de interés que puedan afectar a las condiciones de acceso. 
- Condiciones de acceso: situación legal de acceso y reproducción

5. Área de documentación asociada:

- Unidades de descripción relacionadas con el archivo: relación de la fotografía con otros elementos.

6. Área de notas:

- Notas: para agregar cualquier información considerada básica y que no haya quedado incluida en los otros elementos.

Como Ruiz Rodríguez y Álamo Fuentes hay otros autores que siguen en sus fondos documentales las normas de descripción archivística, las variaciones entre unos y otros atañen sobre todo a la cantidad de elementos que se incluyen o excluyen en la descripción a nivel documental simple. La base de todos es la misma al partir de las ISAD.

\subsection{Modelo para el análisis documental elaborado y propuesto por}

\section{Félix del Valle}

El profesor Félix del Valle elabora ya en el año 1993 un método para llevar a cabo el análisis documental de fotografías que ha sido revisado posteriormente en diversas ocasiones, la última en el año 2001 (Valle, 2001). Para ello propone una ficha de representación elaborada a medida del sistema documental donde en cada campo debe ir la correspondiente información. A continuación se enumeran los campos que componen la ficha y la explicación de la información que deben de contener: 


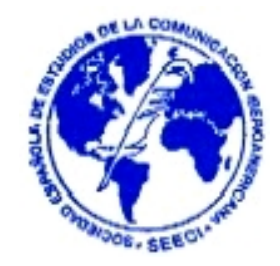

- $\quad$ Número de registro: (NUMREG) Clave numérica o alfanumérica dada al documento cuando entra al sistema.

- Signatura topográfica: (SIGTOP) Clave numérica o alfanumérica que indica dónde está situado físicamente el documento.

- $\quad$ Signatura digital: (SIGDIG) Nombre del archivo digital del documento. Si se trata de una base de datos automatizada esta signatura servirá de enlace parea visualizar el documento.

- $\quad$ Número de negativo: (NUMNEG) Clave numérica o alfanumérica del negativo del documento.

- Otras signaturas: (OTSIG) Correspondientes a copias o reproducciones del documento del documento.

- Fecha de entrada: (FEENT). Campo con formato de fecha que indica cuándo ha entrado la fotografía en el sistema documental.

- Procedencia: (PROC) Se indicará la forma de adquisición (procedencia propia, compra, intercambio, donación) y el lugar de procedencia cuando se considere necesario.

- $\quad$ Fotógrafo: (AUTFOT) Nombre completo y datos biográficos del autor de la fotografía. Este campo puede remitir a una base de datos que incluya datos sobre los fotógrafos.

- $\quad$ Agencia: (AG) Nombre de la agencia de la que procede la foto.

- Título de la fotografía: (TITFOT) Título dado por el fotógrafo o título construido por el documentalista. La construcción de títulos debe de estar normalizada. Se recomienda titular los retratos con el nombre del personaje y la fecha; las fotos de lugares con el nombre del lugar y la fecha y las fotos de situaciones y acontecimientos con su denominación, el lugar y la fecha.

- Título de reportaje: (TITREP) Se utilizará cuando la fotografía pertenezca a un reportaje indicando el nombre dado al reportaje por su autor o un título descriptivo construido por el documentalista con normas similares a las utilizadas en el campo anterior. 
- $\quad$ Fecha de la fotografía: (FEFOT) Campo con formato de fecha que indica con la mayor exactitud la fecha en que fue obtenida la fotografía original.

- $\quad$ Soporte: (SOP) Se indicará si se trata de positivo o negativo, el material que constituye el soporte y la emulsión así como la indicación de blanco y negro o color o características cromáticas.

- $\quad$ Formato: (FORM) Formato (Vertical, horizontal, oval, etc.) y tamaño, en centímetros o en milímetros del documento.

- Estado de conservación: (ESTCON) Se indicará el estado del soporte y de la emulsión.

- Derechos de autor: (DERAUT) Se expresará con claridad quién es el titular de los derechos de utilización de la fotografía.

- Condiciones de uso: (USO) Posibilidad y condiciones de reproducción, copia, difusión, préstamo, venta, etc. Indicación de los contratos.

- Publicado en: (PUB) Se indicará dónde ha sido publicada la fotografía.

Si se trata de un libro se darán los datos de Título/Autor. -- Ciudad: Editorial, año. Si se trata de un periódico o revista el nombre de la publicación y la fecha.

- Óptica: (OPT) Si se considera visualmente reseñable porque afecta de forma significativa al significado de la fotografía o porque interesa al sistema por las características de la base de datos se debe indicar la óptica utilizada para realizar la fotografía: Teleobjetivo, $50 \mathrm{~mm}$, gran angular, ojo de pez.

- Tiempo de pose: (EXP) Como en el campo anterior se puede indicar la velocidad de exposición: Instantánea, ultrarrápida, pose o movimiento.

- Luz: (LUZ) Circunstancias de luz de la fotografía: Día, noche, natural, noche americana, lateral, contraluz, sobrexposición, subexposición, iluminación de estudio.

- Enfoque: (PLA) Tipo de plano utilizado en la composición: Plano general, plano de conjunto, plano entero, plano americano, plano medio, primer plano, plano detalle. 
- $\quad$ Punto de vista: (PVIS) Aumento 1/3 Macro, Aumento 20/20000 Micro, picado, contrapicado, cenital, aéreo (vertical a gran altura), aéreo (vertical a baja altura), aéreo oblicuo, espacial.

- Estructura formal: (ESFOR) Retrato (individual, de estudio, de grupo), Escena, Paisaje, Paisaje urbano, Paisaje interior, Bodegón.

- $\quad$ Resumen: (RES) Descripción en lenguaje natural del contenido de la fotografía.

- Descriptores onomásticos: (DESPER) Personas físicas o jurídicas que aparecen en la fotografía.

- Descriptores geográficos: (DESLUG) Lugares o ámbito geográfico de la fotografía.

- Descriptores temáticos: (DESTEM) Objetos, acciones, actividades, situaciones o conceptos relacionados con la fotografía.

- $\quad$ Autores: (DESAUT) Nombres de autores de obras reproducidas por la fotografía. Se puede utilizar para reproducciones de obras de arte, fotografía de arquitectura, fotografías de películas cinematográficas, etc.

- Obras: (DESOB) Nombres de obras reproducidas en la fotografía. Se utiliza como el campo anterior.

- $\quad$ Notas: (NOT) Información complementaria que no haya tenido cabida en campos anteriores y que se considere necesario añadir.

Estos son los campos totales para el desarrollo de una ficha descriptiva de una imagen según el modelo de Félix del Valle, sin duda el autor recomienda su adaptación según las necesidades de cada centro y de cada imagen, no todas serán susceptibles de contener información en todos los campos. 


\subsection{Sepiades}

SEPIADES $^{4}$ es un proyecto europeo desarrollado en el seno del programa SEPIA ${ }^{5}$ (Safeguarding European Photographic Images for Access) de la Comisión Europea de Preservación y Acceso (ECPA) y publicado en el año 2003. Son una serie de recomendaciones para la catalogación de fondos fotográficos y además diseñan una base de datos para su posible aplicación. El modelo presenta 21 elementos básicos para la descripción, considerados altamente recomendables y recomendaciones para otros niveles más específicos. Presenta diversos niveles de descripción agrupados en tres grandes áreas: administración, procedencia y material.

Casado de Ataola (Casado, 2003) realiza un estudio sobre este modelo llevando a cabo una cierta comparación con las $\operatorname{ISAD}(\mathrm{G})$ y define el modelo de la Comisión Europea como flexible y compatible, un modelo multi-nivel, con una mayor complejidad estructural frente a las ISAD(G). Seguiremos su trabajo para acercarnos a este nuevo modelo y y el propio modelo elaborado en el seno de la Comisión por un grupo de expertos (Aasbo, 2003). Los 21 campos fundamentales del modelo son:

- $\quad$ Código de referencia.

- Identidad administrativa: nombre de la institución. No es necesaria su cumplimentación en el caso de descripción de materiales individuales.

- Código de ingreso. No es necesaria su cumplimentación en el caso de descripción de materiales individuales.

- Ubicación: permanente 0 temporal. No es necesaria su cumplimentación en el caso de descripción de materiales individuales.

- Descripción: correspondería a un resumen del contenido de la imagen. Descripción narrativa de lo que la imagen cuenta. Incluye la información correspondiente al ¿quién?, ¿qué?, ¿dónde? y ¿cómo?

\footnotetext{
${ }^{4}$ A/e: www.knaw.nl/ecpa/sepia/workinggroups/wp5/cataloguing.html

${ }^{5}$ A/e: http://www.knaw.nl/ecpa/sepia/
} 
- $\quad$ Título.

- Persona o entidad responsable de la creación: nombre del careador de la obra, el fotógrafo en el caso de este material que puede ser individual o bien una agencia

- Descriptores/Encabezamientos de materia/clasificación.

- Nombres. Nombres relacionados con la imagen.

- Fecha: de publicación en caso de que haya sido publicada o toma de la imagen en caso contrario. Si no se conoce se aconseja dar un rango de fechas extremas.

- $\quad$ Localización geográfica.

- Restricciones de acceso: existencia de restricciones de acceso y especificación de las mismas. Existencia de copyright y titular del mismo. El modelo recomienda un campo SI/NO para la existencia o no de copyright y luego especificar el poseedor del mismo.

- Relaciones: con otro tipo de documentos iconográficos o textos y estas relaciones pueden ser a nivel interno, con otras que posea en centro o institución, o bien a nivel externo.

- Estatus (original/copia).

- Identificación técnica: color (monocromía o policromía), polaridad (negativo o positivo), tipo (transparencia o reflectante dependiendo de la luz), soporte (papel, plástico, metal, etc.)

\section{- $\quad$ Dimensiones}

- $\quad$ Proceso fotográfico: nombre del proceso fotográfico utilizado (por ejemplo polaroid, imagen digital, láser, etc.)

- $\quad$ Formato de fichero: eps, gif, jpg, tiff, photo cd, etc.

- Referencias: relativas a la publicación de una obra. Este campo se puede utilizar también para referencias bibliográficas de la obra.

- Orígenes de la colección o agrupación. No es necesaria su cumplimentación en el caso de descripción de materiales individuales. 
- Contenido de la colección: incluye información sobre el tipo de material (fotografía, grabado, etc.) y la localización del material. Este campo no se rellena a nivel de descripción de fotografía individual.

Cada uno de estos elementos serán completados en la descripción de manera flexible y dependiendo del nivel de descripción en que nos encontremos: institución, adquisición, colección, agrupación y documento simple. Este último caso siempre supondrá descender a un nivel mayor de desarrollo en la descripción.

\subsection{Modelo para el análisis documental elaborado y propuesto por} García Marco y Agustín Lacruz

García Marco y Agustín Lacruz (García, 1999) han estudiado el análisis de contenido de fotografías centrándose especialmente en las reproducciones de obras artríticas. Estudian todos los procesos, factores y elementos que integran todo el análisis de contenido de la obra artística. Para los datos bibliográficos de las obras recomiendan la utilización de la normativa existente como las ISBD, el formato MARC, las ISAD, de las que ya hemos hablado o las CDWA ${ }^{6}$ para la clasificación y descripción de obras de arte bastante en línea con las ISBD y las ISAD. Además proponen un sistema de indización doble: por una lado a través de lo que denominan niveles de análisis, con tres bloques de índices: relativos a la descripción de la obra, a la identificación y a la interpretación. Un segundo sistema propuesto es a través de facetas que son: agente o personalidad, materia, acción o proceso, espacio y tiempo. Este sistema de facetas está basado en las elaboradas por Ranganathan para el campo de la indización temática.

\footnotetext{
${ }^{6}$ CDWA: Categories for Description of Works of Art. Categorías para la Descripción de Obras de Arte.
} 


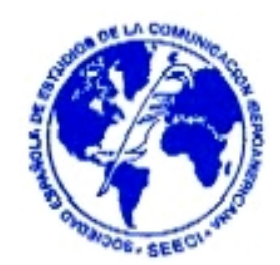

El modelo propuesto quedaría:

- Ficha catalográfica de la obra

- $\quad$ Resumen: realizado en texto libre y en el que se describe de forma inequívoca el contenido de la imagen.

- Datos contextuales de la obra: contextualización de la obra con respecto a la época a la que pertenece

- Indización:

A. Por niveles de análisis:

- Descripción: temas, nombres comunes de personas u objetos 0 acciones. Debe de recoger todas las formas y elementos destacados de forma objetiva. Los gestos y posturas se describen pero no se interpretan en este nivel.

- Identificación: motivos iconográficos representados a través de personas, figuras, objetos, lugares y escenas reconocidos en el primer nivel de la descripción. Aquí se identifican los atributos de cada figura.

- Interpretación: se ocupa del estudio iconológico de la imagen artística. En este nivel hay mayor abstracción, complejidad y subjetividad. Se buscan los significados de la iconografía o nivel anterior.

B. Por facetas:

- Agente o personalidad: agentes con nombre común o nombre propio o de entidad.

- Acción, proceso o movimiento: actividades y conceptos asociados.

- Materia u objeto: materiales, objetos, atributos físicos.

- Espacio: se realizará mediante un tesauro de topónimos.

- Tiempo: se codificará según el formato establecido por el centro. 
- Historia interpretativa: interpretaciones dadas por expertos con respecto a la obra.

- Notas y comentarios: Se pueden incluir notas y comentarios textuales de expertos acerca de la obra.

- Citas: información bibliográfica de la obra

La aplicación de las facetas o niveles de análisis dependerá del centro o institución que lo realice debiendo analizar el grado de complejidad que cada uno le suponga.

\subsection{Modelo para el análisis documental elaborado y propuesto por Jesús Robledano Arillo}

Jesús Robledano nos propone un modelo de representación del contenido temático que él centra en la fotografía de prensa (Robledano, 2002). Con este modelo pretende formalizar las representaciones de las características relevantes de los objetos icónicos, de las propiedades de estos objetos y de sus relaciones. El autor lo entiende como un modelo suficientemente flexible como para que partiendo de él, cada centro adapte su modelo conceptual propio.

El modelo presentado atiende exclusivamente a la representación del contenido de las imágenes debiendo completarse con una representación formal de las mismas. Para el análisis de contenido se proponen cuatro niveles e irán precedidas de un resumen:

- $\quad$ Resumen

- Marco temporal: objeto fecha

- Marco geográfico: objeto lugar

- $\quad$ Descripción icónica: objetos referenciales y no referenciales y relaciones entre objetos. 


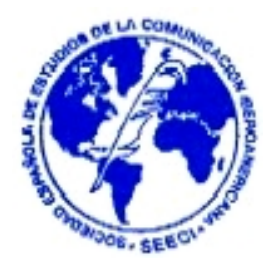

- $\quad$ Descripción temática: por un lado se atenderá al contexto de producción y por otro a las materias complementarias, tanto para la denotación como la connotación.

Además de este modelo Jesús Robledano propone un sistema normalizado para la formalización de representaciones de las características más relevantes de los objetos representados en una imagen, de las propiedades de esos objetos y de sus relaciones. Lo que hace es establecer una serie de clases en las que clasificar los objetos y de cada clase establece sus propiedades, aunque no todos los objetos tendrán todas las propiedades. Tanto las clases como las propiedades quedan abiertas para su adaptación. Las clases son:

- $\quad$ Personas identificadas presentes

- $\quad$ Personas identificadas no presentes

- $\quad$ Personas anónimas: Son aquellos personajes que no podemos identificar con nombre y apellidos.

- Objetos: Para la descripción de objetos no animados en la imagen.

- $\quad$ Animales: Para la descripción de seres vivos que aparecen en la imagen no humanos.

- $\quad$ Medio ambiente: Para la descripción de fenómenos medioambientales

- $\quad$ Acción: Para las acciones que son reflejadas en la imagen

Las propiedades que identifican cada clase serán:

1. Personas identificadas presentes y no presentes:

- $\quad$ Nombre: nombre del personaje

- Apellidos: apellidos

- $\quad$ Alias: apodo, alias, título nobiliario, etc.

- Nacionalidad: nacionalidad del personaje

- $\quad$ Raza: raza del personaje 


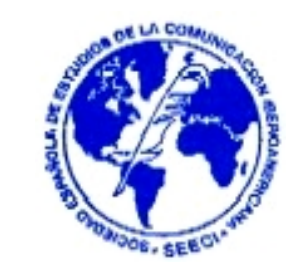

- Status: status social del personaje

- Profesión: profesión

- Institución: institución para la que trabaja

- Cargo: cargo, función que desempeña

- Parte visualizada: primer plano, plano medio, detalle, americano, entero, de conjunto, general

- $\quad$ Punto de vista: de perfil, de frente, de espaldas

- $\quad$ Situación: situación del personaje con respecto al cuadro general

- $\quad$ Profundidad de campo: mayor o menor profundidad dependiendo del objetivo utilizado en la toma

- $\quad$ Calidad: calidad del icono en la imagen

- Vestimenta: vestimenta y color de la misma en caso de considerarse necesario. Ornamentos. Diseño.

- Rasgos: pelo, barba, bigote

- $\quad$ Postura cuerpo: postura que adopta en la imagen

- $\quad$ Postura cabeza: postura que adopta en la imagen

- $\quad$ Postura brazos: postura que adopta en la imagen

- $\quad$ Postura piernas: postura que adopta en la imagen

- Gestos: gestos de la cara o del cuerpo

- Ánimo: estado de ánimo del personaje

- Estado físico: estado físico

- Acción ejecutada: acción que está ejecutando el personaje en el momento de la toma de la imagen. Utilizada para acciones reflexivas que no implican otros elementos (por ejemplo, peinándose). Causa y finalidad de la acción.

- $\quad$ Acción recibida: acción ejecutada sobre el personaje, no por él

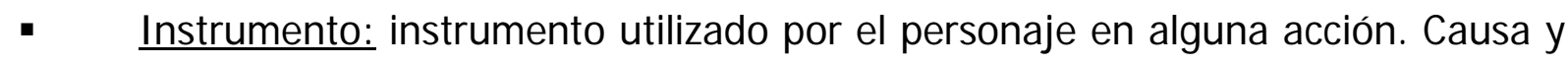
finalidad de la acción. 
2. Personas anónimas:

- Edad: edad aproximada del personaje

- Sexo: sexo

- $\quad$ Nacionalidad: nacionalidad del personaje

- $\quad$ Raza: raza del personaje

- Status: status social del personaje

- Profesión: profesión

- Institución: institución para la que trabaja

- $\quad$ Cargo: cargo, función que desempeña

- Parte visualizada: primer plano, plano medio, detalle, americano, entero, de conjunto, general

- $\quad$ Punto de vista: de perfil, de frente, de espaldas

- $\quad$ Situación: situación del personaje con respecto al cuadro general

- $\quad$ Profundidad de campo: mayor o menor profundidad dependiendo del objetivo utilizado en la toma

- Calidad: calidad del icono en la imagen

- Vestimenta: vestimenta y color de la misma en caso de considerarse necesario. Ornamentos. Diseño.

- Rasgos: pelo, barba, bigote

- $\quad$ Postura cuerpo: postura que adopta en la imagen

- $\quad$ Postura cabeza: postura que adopta en la imagen

- $\quad$ Postura brazos: postura que adopta en la imagen

- $\quad$ Postura piernas: postura que adopta en la imagen

- Gestos: gestos de la cara o del cuerpo

- $\quad$ Ánimo: estado de ánimo del personaje

- Estado físico: estado físico

- Acción ejecutada: acción que está ejecutando el personaje en el momento de la toma de la imagen. Utilizada para acciones reflexivas que no 
implican otros elementos (por ejemplo, peinándose). Causa y finalidad de la acción.

- $\quad$ Acción recibida: acción ejecutada sobre el personaje, no por él

- $\quad$ Instrumento: instrumento utilizado por el personaje en alguna acción. Causa y finalidad de la acción.

3. Objetos:

- Nombre: nombre del objeto

- $\quad$ Punto de vista: de perfil, de frente, de espaldas

- Color: color del objeto

- $\quad$ Diseño: diseño del objeto

- Marca: marca, modelo, título

- $\quad$ Parte visualizada: primer plano, plano medio, detalle, americano, entero, de conjunto, general

- $\quad$ Situación: situación del personaje con respecto al cuadro general

- $\quad$ Profundidad de campo: mayor o menor profundidad dependiendo del objetivo utilizado en la toma

- $\quad$ Calidad: calidad del icono en la imagen

- Estado físico: estado físico

- Acción ejecutada: acción que está ejecutando. Causa y finalidad de la acción.

- $\quad$ Acción recibida: acción ejecutada sobre él.

4. Animales:

- Nombre: nombre del objeto

- Especie: especie animal

- Sexo: sexo

- Raza: raza animal

- $\quad$ Ropa: utilización de ropa. Color y diseño de la misma. 
- $\quad$ Pelo: pelo del animal

- Color: color del animal

- $\quad$ Función: función que ejerce, por ejemplo, perro policía. Indicar institución para la que trabaja.

- $\quad$ Gestos: gestos de la cara o cuerpo

- $\quad$ Postura: postura de cabeza, cuerpo, etc.

- $\quad$ Punto de vista: de perfil, de frente, de espaldas

- $\quad$ Parte visualizada: primer plano, plano medio, detalle, americano, entero, de conjunto, general

- $\quad$ Situación: situación del personaje con respecto al cuadro general

- $\quad$ Profundidad de campo: mayor o menor profundidad dependiendo del objetivo utilizado en la toma

- $\quad$ Calidad: calidad del icono en la imagen

- Estado de ánimo: estado de ánimo del animal

- Estado físico: estado físico

- $\quad$ Acción ejecutada: acción que está ejecutando. Causa y finalidad de la acción.

- $\quad$ Acción recibida: acción ejecutada sobre él.

5. Medio ambiente:

- $\quad$ Luz: luz

- Meteoro: para fenómenos como lluvia, nieve, niebla, tormenta, viento, etc.

- Elementos: elementos como el humo

- Causa: a causa de

- Color: color

6. Acción:

- Ejecutor de la acción: puede ser humano o cualquier tipo de ser vivo u objeto

- $\quad$ Receptor de la acción: personas, seres vivos u objetos que reciben la acción 


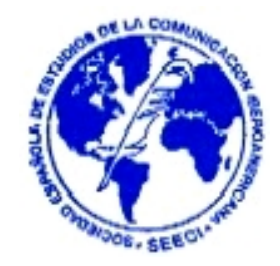

Como en todos los modelos vistos esto representaría el total de la descripción pero en cada imagen se adaptará a las características de las mismas. En la misma obra en que se propone este modelo para el análisis de contenido se dan pautas para la realización del análisis formal de la fotografía. Con este modelo se pretende facilitar la descripción de los objetos/iconos representados en las imágenes y facilitar a través de su descripción completa la posterior recuperación.

\subsection{Modelo para el análisis documental elaborado y propuesto por} un grupo de investigación de la Universidad Jaume I

Por último vamos a analizar un complicado y extensísimo modelo propuesto por el grupo de investigación del Área de Comunicación Audiovisual y Publicidad de la Universidad Jaume I de Castellón. Realizan una investigación entre los años 2001 y 2003 para generar una serie de materiales didácticos sobre recursos expresivos y narrativos para fotografía, imagen cinematográfica y lenguaje publicitario. A partir de esta investigación desarrollan una propuesta metodológica para el análisis de la imagen fotográfica que se plasma en una ficha con 59 parámetros para ser analizados. Los parámetros se organizan en una serie de niveles llamados contextual, morfológico, compositivo e interpretativo.

Para conocer este modelo vamos a ver los parámetros que el grupo de investigación considera que debemos analizar:

1. Nivel contextual

- Título

- Autor y nacionalidad del mismo

- Procedencia de la imagen

- Género: clasificación genérica como puede ser retrato, desnudo, fotografía social, de prensa, paisaje, fotorreportaje, etc. 
- Movimiento: situar la fotografía en una determinada corriente o movimiento o escuela artística.

- B/N o color

- Formato: aquí recogeremos el tamaño y dimensiones de la copia

- Cámara: tipo de cámara utilizada en caso de conocerse

- Soporte

- Objetivo: teleobjetivo, gran angular, normal, ojo de pez

- Otras informaciones técnicas: utilización de flash, iluminación, filtros, etc.

- Hechos biográficos relevantes sobre el autor

- Comentarios críticos sobre el autor

2. Nivel morfológico

- Descripción del motivo fotográfico

- Punto: grano fotográfico más o menos visible o pixels en el caso de la foto digital

- Línea: sucesión de puntos que por su naturaleza transmite energía, movimiento, etc.

- Planos-Espacio

- Escala: plano medio, americano, entero, general, detalle, plano conjunto

- Forma: círculo, cuadrado, triángulo, etc.

- Textura

- Nitidez de la imagen

- Iluminación: artificial, natural, suave, etc.

- Contraste

- $\underline{\text { Tonalidad }}$

- Otros elementos que no hayan podido ser incluidos en las categorías anteriores 
3. Nivel compositivo

- Perspectiva

- $\underline{\text { Ritmo }}$

- Tensión

- Proporción

- Distribución de pesos

- Ley de tercios: La fuerza visual de un elemento plástico será más intensa cuando esté situado en alguno de los puntos de intersección de las llamadas líneas de tercios. La obtención de estas líneas de tercios se consigue al dividir la imagen en tres partes iguales en horizontal y en vertical, tomando como referencia los límites horizontal y vertical del propio marco de la fotografía.

- Orden icónico

- Recorrido visual

- Estaticidad o dinamicidad

- $\underline{\text { Pose }}$

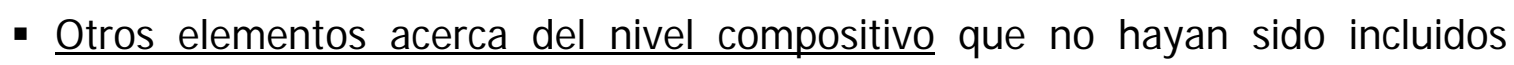
antes

- Comentario: conviene realizar un comentario conjunto de todos los elementos vistos anteriormente.

- Campo o fuera de campo: Espacio representado en la materialidad de la imagen.

- Espacio de representación abierto o cerrado

- Espacio interior o exterior

- Espacio concreto o abstracto

- Espacio profundo o plano

- Habitabilidad del espacio por el espectador

- Puesta en escena

- Otros comentarios en cuanto al espacio no expresados anteriormente

- Instantaneidad de la representación 
- Duración

- Atemporalidad

- Tiempo simbólico de la imagen

- Tiempo subjetivo de la imagen

- Secuencialidad: orden secuencial en la lectura de la imagen

- Otros comentarios sobre el tiempo de representación

4. Nivel interpretativo

- Punto de vista físico

- Actitud de los personajes

- Calificadores

- Transparencia, verosimilitud

- Marcas textuales

- Miradas de los personajes (si miran o no hacia la cámara)

- Enunciación: realismo o no de una escena

- Relaciones intertextuales

- Otros comentarios sobre el nivel interpretativo de la obra.

Al final debe de realizarse una interpretación global del texto iconográfico, esta vez de carácter más subjetivo reconociendo todos los posibles significados que las formas, objetos, figuras, colores, etc. nos puedan sugerir. Es evidente que no en todas las imágenes se podrán completar los campos propuestos por los autores.

\section{Conclusiones}

Los datos obtenidos del análisis de las imágenes y el estudio de los diferentes modelos muestran como sigue siendo necesario un mayor consenso y normalización de los centros e instituciones. Como ya se adelantó hay casi tantos modelos como centros que custodian y conservan fotografías y los intentos de proponer modelos 


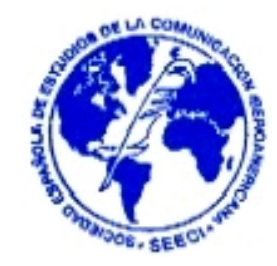

para ser utilizados no han mejorado mucho la situación ya que se proponen modelos de consenso pero cada centro sigue elaborando el suyo y no se opta por modelos comunes.

La parte más normalizada es la referente al análisis formal en donde las ISBD y las ISAD ganan terreno. En el análisis realizado con las fotografías utilizando estas dos normas se ha podido comprobar como las ISBD se quedan cortas en cuanto a los campos de descripción y a la información que aportan para la recuperación. Es cierto que el campo de notas deja abierta la posibilidad de incorporar cualquier tipo de información que no se haya podido incluir en el resto de áreas, pero esta solución es algo engorrosa y desestructurada de cara al usuario final. Además como se ha señalado en numerosas ocasiones las ISBD son un formato poco amigable de cara a los usuarios, que utiliza una terminología demasiado profesional, que no es transparente en cuanto a la organización en unas áreas que el usuario desconoce y con una rígida puntuación que separa unos elementos de otros y que el usuario no tiene por qué conocer. Si en la actualidad se critica cada vez más este formato en la descripción de material bibliográfico, su utilización para la descripción de imágenes es igual de problemática.

Las ISAD siguen un formato más claro de cara al usuario, etiquetado, con un lenguaje menos profesional y transparente y hacen más sencilla la recuperación. El problema es que esta norma no está demasiado extendida para la descripción de unidades documentales como una única fotografía, y se utiliza más para otros niveles de descripción. En los archivos la descripción de documentos textuales no se suele hacer a nivel de unidad documental y a la hora de describir imágenes no está aún muy extendido el uso de esta norma. Podemos decir que se utiliza sobre todo a nivel institucional, de archivos públicos, por una extensión de su uso con respecto al material textual, pero no es así en el caso de archivos privados. La descripción en áreas y en distintos niveles permite un nivel de profundidad mucho mayor que las ISBD. La extensión de una normativa como las ISAD permitiría compartir información 


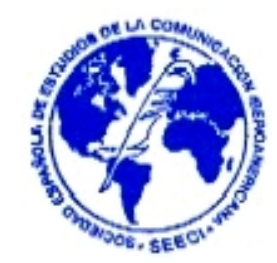

a los centros de trabajo, facilitando el intercambio de datos y reduciendo los tiempos y costes de trabajo.

El modelo SEPIADES es bastante similar a las ISAD. En su elaboración no se ha pretendido desplazar a otros modelos sino complementarlos, pero en realidad a veces esta duplicidad de modelos dificulta el trabajo. No tiene demasiado sentido que grupos de expertos se reúnan duplicando esfuerzos y trabajos, el aunar esfuerzos y caminos de investigación supondría un verdadero avance y facilitaría el trabajo diario de los centros. La compatibilidad de la norma de descripción ISAD con el modelo SEPIADES puede plantear problemas porque muchos de los elementos descritos en ISAD se corresponden con más de un elemento en SEPIADES, por lo tanto no hay una buena interconexión. Puede suponer grandes dificultades pasar de un modelo a otro. A la hora de desarrollar SEPIADES esto se debería de haber tenido en cuenta.

Con respecto a los modelos elaborados por diferentes autores hemos visto como las diferencias entre unos y otros se basan en la profundidad de la descripción fundamentalmente. Su profundización permite realizar análisis de contenido mucho más desarrollados que con la normativa ISAD por ejemplo. Es fundamental la elaboración de un resumen en texto libre que permita describir los contenidos de las imágenes. Estos modelos permiten la introducción de elementos connotados y denotados en la fotografía además de información de contexto, todos estos datos son esenciales para la correcta recuperación de las imágenes. Además son mucho más flexibles y transparentes en la elaboración de etiquetas que identifican los campos y para el usuario final y esto facilita enormemente la recuperación. Otra diferencia entre ellos es el nivel de complicación que supone su implementación, desde modelos más sencillos como el de Félix del Valle, hasta un modelo terriblemente complicado como el desarrollado por la Universidad Jaume I que exige unos elevados conocimientos de fotografía y técnica fotográfica. Un modelo así no tiene una aplicación práctica muy factible, es demasiado complicada su aplicación 


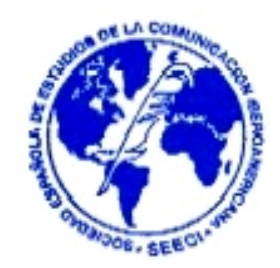

además de muy costosa. La indización y documentación sobre la imagen puede llevar a un analista varias horas de trabajo, evidentemente esto supone unos costes que casi ningún centro se podría permitir. Su aplicación quedaría restringida por tanto a un ámbito académico y de investigación y no tanto a un centro de conservación y difusión con otras tipologías de usuarios.

El modelo que han desarrollado García Marco y Agustín Lacruz es muy completo, sencillo de aplicación, aunque sobre todo muy adaptado al análisis de obras artísticas pero podría adaptarse perfectamente a otras temáticas. El análisis a través de facetas que parece que en el texto casi nunca ha sido aplicado por considerarlo de una excesiva complicación se adapta perfectamente y de manera sencilla al análisis de fotografías, permitiendo abarcar todos los puntos de vista susceptibles de ser analizados en una imagen. Quizás se quede algo corto en cuanto al tratamiento de características técnicas como sí lo hace por ejemplo el de Félix del Valle analizando puntos fundamentales para una imagen como la forma, el soporte, estado de conservación, derechos sobre la imagen, luz, planos, etc. que el modelo de García Marco no trata.

Un campo que no se desarrolla mucho en ninguno de los modelos es el relativo a los derechos de uso de la imagen y protección de los contenidos, derechos de personalidad de aquellos que aparecen en las imágenes. No sólo hay que establecer y aclarar quiénes son los poseedores del copyright de una imagen si no las limitaciones en el uso de la misma. Son conocidos numerosos casos como el de una fotografía de Robert Doisneau aparecida en origen para ilustrar un reportaje sobre tascas en París, en donde aparecen un hombre y una mujer en un local y que con el paso de los años se vendió y reutilizó apareciendo esta vez para ilustrar un texto sobre la prostitución en los Campos Elíseos, con la consiguiente denuncia del personaje fotografiado a la revista, la agencia que vendió la imagen y al fotógrafo (Valle, 2001). Esto no es un hecho aislado, muchas veces se difunden imágenes sin un control de los derechos sobre la misma y sin un control sobre sus contenidos y 


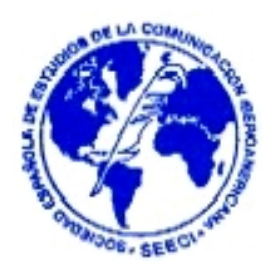

esto puede suponer graves problemas para el centro difusor. El archivo, como depositario de la imagen, es responsable de su uso. Esto debe paliarse ya desde el momento de entrada de la imagen al archivo y una buena herramienta podría ser un campo específico que formase parte del análisis documental donde además se expresasen recomendaciones para evitar usos indebidos. El documentalista debe contribuir a evitar estos usos a través de una correcta identificación.

¿Qué modelo podemos decir que es el más apropiado para el análisis documental de fotografías sin perder de vista la recuperación por parte de diferentes usuarios? Pues en realidad todos y ninguno. El mejor modelo será al final el que mejor se adapte a las necesidades de cada centro. Hay que tener en cuenta múltiples variables como el tipo de usuarios, el tipo de material, la temática y especialización de nuestros fondos, los sistemas que se van a utilizar para la recuperación, el personal con el que se cuenta para el análisis, los presupuestos, etc. De todo esto dependerá el modelo elegido. Quizás por esto exista esa multiplicidad de modelos porque al final cada centro debe de estudiar sus propias necesidades para determinar cómo será su análisis.

Como retos para el futuro habría que consensuar algo más los modelos utilizados. Cada centro debe poderlos adaptar a sus necesidades pero el punto de partida debería de ser más común. Esto facilitaría enormemente el trabajo en colaboración y ahorraría costes que podrían dirigirse a temas de calidad. También hay que trabajar en el desarrollo de herramientas de indización que recojan todas las formas de transmitir los contenidos, las sensaciones, emociones, etc. de una imagen. Ahora mismo se sigue realizando esta indización a través de lenguajes controlados con un enfoque puramente textual que no permiten reflejar todos los contenidos de una imagen. En definitiva abandonar la perspectiva de que el análisis de imágenes sea un reflejo del análisis textual y cobre entidad propia. 


\section{Bibliografía}

AASBO, Kristin; ORTEGA GARCÍA, Isabel; ISOMURSU, Anne; JOHANSSON, Torsten y KLIJ N, Edwin (2003). Sepiades: recommendations for cataloguing photographic collections. Amsterdam: European Commission on Preservation and Access. Disponible en: http://www.knaw.nl/ecpa/sepia/workinggroups/wp5/sepiadestool/sepiadesdef.pdf

AGUSTÍN LACRUZ, M. Carmen (1997). Metodología para la indización de documentos no textuales: algunas precisiones a propósito de los documentos gráficos y audiovisuales. En Organización del conocimiento en sistemas de información y documentación. Actas del III Encuentro de isko-España, Getafe, 19 al 29 de noviembre de 1997. Zaragoza: Universidad de Zaragoza, 1999, p. 129-132.

CASADO DE ATAOLA, Luis (2003). Un proyecto europeo para la descripción de materiales fotográficos. Boletín acal. 2003, № 47-48, p. 66-69.

CLAUSÓ GARCÍA, Adelina (1999). Descripción de materiales gráficos. En VALLE GASTAMINZA, Félix del (ed.) (1999): Manual de documentación fotográfica, Síntesis. Madrid. DOMÈNECH FERNÁNDEZ, Silvia (1999): La indexació de fotografies. Métodos de información. 1999, vol. 6, no 34, p. 61-66.

GARCÍA MARCO, Francisco Javier y AGUSTÍN LACRUZ, María del Carmen (1999): El análisis de contenido de las reproducciones fotográficas de obras artísticas. En VALLE GASTAMINZA, Félix del (ed.) (1999) Manual de documentación fotográfica, Síntesis. Madrid.

ISAD (2000) (g): Norma Internacional General de Descripción Archivística. 2a ed. Madrid: Subdirección de los Archivos Estatales, 2000.

ISBD (1993) (nbm). Descripción bibliográfica internacional normalizada para materiales no librarios. Madrid: anabad, 1993.

MADRID DÍAZ, M. Victoria (1997). El análisis de contenido en la imagen fija: una propuesta para la base de datos gráfica del iaph. En Sistemas y políticas de información en el Estado de 


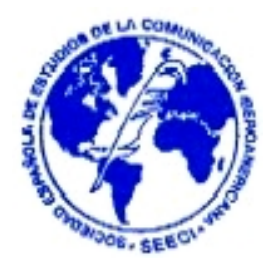

las autonomías. Situación y perspectivas. Actas de las I Jornadas Andaluzas de Documentación, jadoc'97. Sevilla, 13 al 14 de noviembre de 1997. Sevilla: Asociación Andaluza de Documentalistas, 1997, p. 257-265.

MARZAL FELICl, José Javier (2004). Una propuesta de análisis de la imagen fotográfica mediante la utilización de tecnologías digitales e informacionales. En El análisis de la imagen fotográfica. I Congreso de teoría y técnica de los medios audiovisuales. Castellón, 13 al 15 de octubre de 2004.2 Disponible http://apolo.uji.es/analisisfotografico/analisis/PDFsCongreso/J ose\% 20] avier\% 20Marzal\% 20F elici.pdf

MOREIRO GONZÁLEZ, José Antonio (2001). Significantes y significados en el análisis documental de la imagen. En Pinto Molina, María (ed.) Catalogación de documentos: teoría y práctica. 2a ed. rev. y act. Madrid: Síntesis, 2001, p. 395-418.

ORTEGA, Isabel (1999). Los materiales fotográficos. En DíEZ CARRERA, Carmen (coord.) (1999): Los materiales especiales en las bibliotecas, Ediciones Trea. Gijón.

ROBLEDANO ARILLO, Jesús (2002). El tratamiento documental de la fotografía de prensa: sistemas de análisis y recuperación. Archiviana. Madrid.

RUIZ RODRÍGUEZ, Antonio Ángel y ÁLAMO FUENTES, Inés del (1998). La integración de los archivos de imágenes en el entorno ciudadano. La normalización de los procesos descriptivos. En Los sistemas de información al servicio de la sociedad. VI Jornadas Españolas de Documentación. Valencia: fesabid, 1998. Disponible en: http://fesabid98.florida-uni.es/Comunicaciones/a_angel/a_angel.htm

SHATFORD LAYNE, Sara (1994). Some issues in the indexing of images. Journal of the American Society of Information Science. 1994, vol. 45, no 8, p. 583-588.

VALLE GASTAMINZA, Félix del (2001). El análisis documental de la fotografía. Cuadernos de documentación multimedia. 1993, № 2. Ed. rev. 2001. Disponible en: http://www.ucm.es/info/multidoc/prof/fvalle/artfot.htm 
VALLE GASTAMINZA, Félix del (1994). “Consideraciones sobre el análisis documental de la fotografía de prensa". Revista General de Información y Documentación. 1994, vol. 4, no 2, pág. 169-173.

VALLE GASTAMINZA, Félix del (2002). Indización y representación de documentos visuales y audiovisuales. En LÓPEZ YEPES, José (coord.) (2002): Manual de ciencias de la documentación, Pirámide. Madrid. 